\title{
Protective Effect of White-fleshed Peach (Prunus persica (L.) Batsch) on Chronic Nicotine-induced Toxicity
}

\author{
Hyun-Jeong Kim ${ }^{1}$, Kwang-Kyun Park ${ }^{1,2}$, Won-Yoon Chung ${ }^{1,2}$, Sun Kyoung Lee ${ }^{1}$, Ki-Rim Kim ${ }^{3}$ \\ 'Department of Oral Biology and Oral Cancer Research Institute, BK21 PLUS Project, Yonsei University College of Dentistry, ${ }^{2}$ Department of Applied \\ Life Science, The Graduate School, Yonsei University, Seoul, ${ }^{3}$ Department of Dental Hygiene, Kyungpook National University, Sangju, Korea
}

\begin{abstract}
Background: Nicotine is a major toxic component of tobacco smoke and has been recognized as a risk factor to induce oxidative tissue damage, which is a precursor to cardiovascular diseases, lung-related diseases, and cancers. Peaches (Prunus persica) have been used for the treatment of degenerative disorders, such as hypermenorrhea, dysmenorrhea, and infertility in Asian countries. In this study, we investigated the effects of white-fleshed peach on the excretion of nicotine metabolites and 1-hydroxypyrene in smokers and chronic nicotine-induced tissue damages in mice.

Methods: The concentrations of cotinine and 1-hydroxypyrene were measured in urine of smokers before or after intake of white-fleshed peaches. In addition, ICR mice were injected with nicotine $(5 \mathrm{mg} / \mathrm{kg}$ body weight) and then orally administered with white-fleshed peach extracts (WFPE) (250 or $500 \mathrm{mg} / \mathrm{kg}$ body weight) for 36 days. The oxidative stress parameters and the activities of antioxidant enzymes were measured in liver and kidney tissues. Also, histological changes and nitrotyrosine expression were assessed.

Results: Intake of white-fleshed peaches increased the urinary concentration of nicotine metabolites and 1-hydroxypyrene in $91.67 \%$ and $83.33 \%$ of smokers, respectively. WFPE decreased the malondialdehyde levels and recovered the activities of antioxidant enzymes in nicotine-injected mice. In addition, WFPE inhibited nitrotyrosine expression and inflammatory responses in the liver, kidney, and lung tissues of nicotine-treated mice.

Conclusions: White-fleshed peaches may increase the metabolism of toxic components in tobacco smoke in smokers and protect normal tissues against nicotine toxicity in mice. Therefore, supplementation of white-fleshed peaches might be beneficial to smokers.
\end{abstract}

(J Cancer Prev 2017;22:22-32)

Key Words: Prunus persica, Nicotine, Toxicity, Oxidative stress

\section{INTRODUCTION}

Smoking is a critical public health problem that negatively affects quality of life. It has been strongly implicated as a risk factor for chronic obstructive pulmonary disease, lung cancer, and cardiovascular disorders. ${ }^{1}$ Furthermore, cigarette smoking has been considered as an important risk factor that leads to cancers of the stomach, liver, and pancreas, as well as renal cell carcinoma and transitional cell carcinomas of the urinary bladder and renal pelvis. ${ }^{2.4}$

Nicotine, a major alkaloid constituent of tobacco, is metabo- lized to several metabolites and excreted into the urine. In saliva or urine samples, nicotine metabolites have been used to evaluate smoking status quantitatively. Nicotine and its major metabolite, cotinine, have carcinogenic effects because they bind to nicotinic acetylcholine receptors on non-neuronal cells. ${ }^{5.6}$ Chronic nicotine exposure induces lipolysis and hepatotoxicity. ${ }^{7.8}$ It results in oxidative stress by inducing the generation of reactive oxygen species (ROS). Previous experiments have shown that administration of nicotine to rats resulted in increased levels of lipid peroxidation products. ${ }^{9}$ Chronic nicotine exposure also causes oxidative damages by decreasing the activity of endo-

Received December 22, 2016, Revised February 28, 2017, Accepted March 1, 2017

Correspondence to: Ki-Rim Kim

Department of Dental Hygiene, Kyungpook National University, 2559 Gyeongsang-daero, Sangju 37224, Korea

Tel: +82-54-530-1422, Fax: +82-54-530-1429, E-mail: Kirim0804@gmail.com

Copyright (C) 2017 Korean Society of Cancer Prevention

(c) This is an Open Access article distributed under the terms of the Creative Commons Attribution Non-Commercial License (http://creativecommons.org/licenses/by-nc/4.0) which permits unrestricted non-commercial use, distribution, and reproduction in any medium, provided the original work is properly cited. 
genous antioxidants, such as catalase (CAT) and superoxide dismutase (SOD). ${ }^{10}$ These evidences support the role of oxidative stress in the toxicity of nicotine.

Several natural products and compounds, including flavonoids, have been used to protect against toxicity induced by long-term drug treatments of chronic diseases or cancers and carcinogenic xenobiotics existing in many junk foods, alcohol, and other environmental toxicants. Peaches (Prunus persica (L.) Batsch), including various species, are consumed and used as a dietary supplement worldwide. P. persica seeds (Persicae Semen; Tounin) are well-known in many Asian countries as a traditional medicine. The chemical constituents of peach seeds, including structurally simple glycosides, have significant anti-tumor activity. ${ }^{11}$ The ethanol extract of $P$. persica also inhibits mast cell-mediated allergic inflammatory reactions in in vivo models. ${ }^{12}$ Previous studies reported that the extract of $P$. persica flesh protects against hepatotoxicity and nephrotoxicity induced by cisplatin, which is prescribed to treat solid tumors in mice. ${ }^{13,14}$ Low-acid white-fleshed peaches are most popular in Asian countries, such as Korea, China, and Japan, while Europeans and North Americans consume mainly yellow-fleshed peaches with high acidity and low sweetness. Therefore, we investigated whether intake of white-fleshed peaches affects the excretion of nicotine metabolites and 1-hydroxypyrene in the urine of smokers. Furthermore, we evaluated the protective effect of white-fleshed peach extracts (WFPE) on chronic nicotine-induced tissue toxicity by determining the biochemical parameters and histological examination in an animal model.

\section{MATERIALS AND METHODS}

\section{Materials}

(-)-Cotinine, 1-hydroxypyrene, nicotine hydrogen bitartrate, sodium acetate, potassium cyanide, chloramine, barbituric acid, and $\beta$-glucuronidase/arylsulfatase were obtained from Sigma-Aldrich (St. Louis, MO, USA). Methanol was purchased from Merck (Darmstadt, Germany). All reagents used in this study were of analytical grade. The white-fleshed fruits of Prunus persica (L.) Batsch (Family Rosaceae; peaches) were purchased at the Kyeonggi Dong-Boo Fruit Agriculture Co. (Incheon, Korea), where a voucher specimen (PE20060801) has been deposited.

\section{Subjects}

Twelve healthy adult Korean male smokers volunteered for the study to investigate the effects of white-fleshed peaches on the excretion of nicotine metabolites and 1-hydroxypyrene into the urine. Subjects signed the informed consent form; smoking status and number of cigarettes per day were assessed using a self-administrated questionnaire. Urine, saliva, and blood were collected before intake of white-fleshed peaches and four days after intake. Participants intaked three fruits a day for four days. Before the study began, informed written consent was collected from all participants according to the ethical guidance of the Institutional Review Board of Yonsei University College of Dentistry, Seoul, Korea.

\section{Determination of nicotine metabolite}

An aliquot of urine sample $(500 \mu \mathrm{L})$ was mixed with $500 \mu \mathrm{L}$ ethanol, $200 \mu \mathrm{L} 4 \mathrm{M}$ acetate buffer ( $\mathrm{pH} 4.7$ ), $100 \mu \mathrm{L} 1.5 \mathrm{M}$ potassium cyanide, $100 \mu \mathrm{L} 0.44 \mathrm{M}$ chloramine, and $500 \mu \mathrm{L} 78 \mathrm{mM}$ barbituric acid. As a reference, $500 \mu \mathrm{L}$ urine sample were diluted with $1.4 \mathrm{~mL}$ deionized water. After 100 minutes at room temperature, absorbance was measured at $508 \mathrm{~nm}$ using a microplate reader (BIO-RAD Laboratories, Hercules, CA, USA). Since values obtained by the colorimetric method were sums of nicotine metabolites, we expressed them as cotinine equivalent concentrations using cotinine as a standard.

\section{Determination of 1-hydroxypyrene}

Ten milliliters of urine were transferred to a flask. The $\mathrm{pH}$ of the solution was adjusted to 5.0 with $1 \mathrm{M} \mathrm{HCl}$, and then $2.5 \mathrm{~mL} 0.5$ $\mathrm{M}$ acetate buffer ( $\mathrm{pH}$ 5.0) were added. After addition of $20 \mu \mathrm{L}$ $\beta$-glucuronidase/arylsulfatase (131,400 units/mL and 7,500 units $/ \mathrm{mL}$ at $\mathrm{pH} 5.0$ and $37^{\circ} \mathrm{C}$, respectively), the flask was placed in a shaker for 16 hours at $37^{\circ} \mathrm{C}$ to completely hydrolyze the polycyclic aromatic hydrocarbons (PAHs) hydroxide conjugates. After hydrolysis, samples were centrifuged at $850 \times g$ for 10 minutes, and the supernatant was used for solid phase extraction. The Discovery C18 solid phase extraction cartridge (Supelco, Bellefonte, PA, USA) was pretreated with $5 \mathrm{~mL}$ of methanol and $5 \mathrm{~mL}$ deionized water. The hydrolyzed urine sample was loaded onto the cartridge at a flow rate of $<1$ $\mathrm{mL} / \mathrm{min}$. The column was washed with $10 \mathrm{~mL}$ of water and $10 \mathrm{~mL}$ $30 \%$ methanol to remove the matrix interferences. After the cartridges were dried completely, the trapped metabolites were eluted with $4 \mathrm{~mL}$ methanol. The eluate was concentrated almost to dryness under a gentle stream of nitrogen and dissolved in 1 $\mathrm{mL}$ methanol. The solution was filtered through a $0.2-\mu \mathrm{m}$ filter and stored at $-20^{\circ} \mathrm{C}$ before the high-performance liquid chromatography (HPLC) analysis. The stock standard solution $(0.2 \mathrm{~g} / \mathrm{L})$ of 1-hydroxypyrene was prepared by dissolving $5.0 \mathrm{mg}$ of solid standard in methanol in a 25 -mL volumetric flask. Dilutions 
in methanol were prepared to concentrations of 100 and $1.0 \mu \mathrm{g} / \mathrm{L}$ and stored in the dark at $4^{\circ} \mathrm{C}$.

The Shimadzu HPLC system consists of a model SCL-10AVP system controller, a model LC-10ADVP micro-plunger pump, a model DGU-14A degasser, a model SIL-10ADVP auto sampler, a model CTO-10ASVP column oven, and a model RF-10AXL fluorescence detector (Shimadzu, Kyoto, Japan). The system was monitored by Shimadzu Class VP software (ver. 6.12 SP3). The reverse-phase chromatography was performed on a Discovery C18 column ( $150.0 \times 4.6 \mathrm{~mm}, 5 \mu \mathrm{m}$ particle size; Supelco). The mobile phase was methanol-water $(60: 40, v / v)$ at a flow-rate of 1 $\mathrm{mL} / \mathrm{min}$. The injection volume was $10 \mu \mathrm{L}$, and the total run time was 30 minutes. The retention time of 1-hydroxypyrene in these conditions was 17 minutes. The eluted peaks were monitored at excitation and emission wavelengths of 242 and $388 \mathrm{~nm}$, respectively.

\section{Measurement of creatinine and cotinine}

Urinary creatinine levels were evaluated spectrophotometrically, using commercially available kits (Asan Pharmaceutical, Seoul, Korea). Salivary cotinine levels were determined using a High Sensitivity Salivary Cotinine Quantitative Enzyme Immunoassay kit (Salimetrics, State College, PA, USA).

\section{Preparation of white-fleshed peach extracts}

The pericarps and seeds were removed from peaches, and the collected white-flesh was extracted thrice in five volumes $(\mathrm{w} / \mathrm{v})$ of $80 \%$ ethanol for 48 hours at room temperature. The extracts were filtered, concentrated by vacuum evaporating the solvent in a rotary evaporator, and freeze-dried. The dried extracts of white-fleshed peaches were stored at $-20^{\circ} \mathrm{C}$.

\section{Animals and experimental design}

Male ICR mice (25-30 g body weight, 5-week-old) were purchased from the Central Laboratory Animal Inc. (Seoul, Korea). They were provided free access to a commercial rodent chow (Daejong Inc., Seoul, Korea) and tap water ad libitum. All animals were housed under specific pathogen-free conditions with a 12 hours light-dark cycle and a relative humidity of $55 \% \pm$ $5 \%$ at $25^{\circ} \mathrm{C} \pm 2{ }^{\circ} \mathrm{C}$. All experimental procedures were performed in accordance with the guidelines and regulation for the use and care of animals established by the Animal Ethics Committee of Yonsei University College of Dentistry (IACUC Approval Number: 2012-0092). Mice randomly divided into five groups, each with six animals of similar average body weights. Group I as control mice were intraperitoneally injected with saline. Group II was administrated WFPE daily at a dose of $500 \mathrm{mg} / \mathrm{kg}$ body weight orally alone. Group III was injected with nicotine hydrogen bitartrate intraperitoneally at a dose of $5 \mathrm{mg} / \mathrm{kg}$ body weight daily for 5 weeks. Group IV or V received daily intraperitoneal injections of nicotine $5 \mathrm{mg} / \mathrm{kg}$ and oral administration of WFPE $250 \mathrm{mg} / \mathrm{kg}$ or $500 \mathrm{mg} / \mathrm{kg}$ for 5 weeks. The individual body weights of all animals were measured once every other day. At the end of the experiment, all mice were anesthetized, and blood samples were taken from the intracardiac puncture. The blood samples were allowed to clot at room temperature for 2 hours, and then centrifuged at 2,000 $\times g$ for 20 minutes to obtain the serum. The serum samples were stored at $-80^{\circ} \mathrm{C}$ to assess hepatic and renal function. The liver, kidney, and lung tissues were removed for the biochemical assay and histopathological examination.

\section{Determination of serum biochemical parameters}

In order to evaluate hepatic function, serum alanine aminotransferase (ALT) and aspartate aminotransferase (AST) levels were measured. Serum blood urea nitrogen (BUN) and creatinine levels were assessed as indicators of renal function. All biochemical assays were performed using commercially available kits from YeongDong Pharmaceutical Co. (Seoul, Korea) according to the manufacturer's instructions. The absorbance of all biochemical assays were measured in a POLARstar Omega microplate reader (BMG LABTECH, Offenburg, Germany).

\section{Preparation of tissue homogenates}

The liver and kidney tissues isolated from all mice were immediately washed with an ice-cold PBS ( $\mathrm{pH} 7.4)$ to remove the blood. The tissues were cut into small pieces with scissors on ice. The sliced tissues (100 mg) were subsequently homogenized in $1.0 \mathrm{~mL}$ of cold $1.15 \% \mathrm{KCl}$ buffer (pH 7.4) including $100 \mathrm{mM}$ phenylmethylsulfonyl fluoride. The homogenates were centrifuged at $800 \times g$ for 20 minutes at $4^{\circ} \mathrm{C}$. Aliquots of the supernatant were collected and stored at $-80^{\circ} \mathrm{C}$ to measure the levels of lipid peroxidation and glutathione (GSH) and the activity of antioxidant enzymes. Total protein concentrations in the supernatants were determined using a bicinchoninic acid protein assay kit (Pierce Biotechnology Inc., Rockford, IL, USA).

\section{Determination of lipid peroxidation and glutathione levels}

In the homogenates of the liver and kidney tissues, the level of malondialdehyde (MDA), an indicator of lipid peroxidation, was determined by monitoring thiobarbituric acid (TBA) reactive substance formation as described previously. ${ }^{15}$ Lipid peroxi- 
dation was expressed in terms of MDA equivalents using an extinction coefficient of $1.56 \times 10^{5} \mathrm{M}^{-1} \mathrm{~cm}^{-1}$ and the final MDA level is represented as $\mu$ mol per $g$ tissue. MDA reacts with TBA in the homogenate sample to form a colored complex that has an absorbance at $532 \mathrm{~nm}$ in a spectrophotometer. 1,1,3,3-tetramethoxypropane was utilized as a standard curve. The total GSH content of the tissue homogenates was detected at $412 \mathrm{~nm}$ colorimetrically using a reaction with Ellman's reagent [5,5'-dithiobis(2-nitrobenzoic acid) or DTNB] ${ }^{16} \mathrm{GSH}$ level is expressed as $\mu \mathrm{M}$ per g tissue.

\section{Measurement of antioxidant enzyme activities}

SOD activity was measured using the SOD determination kit (Sigma-Aldrich) in accordance with the manufacturer's protocols. SOD assay kit-WST allows SOD assaying by utilizing Dojindo's highly water-soluble tetrazolium salt, WST-1 [2-(4-lodophenyl)-3-(4-nitrophenyl)-5-(2,4-disulfophenyle)-2H-tetrazolium, monosodium salt] for detection of the superoxide anions generated by xanthine oxidase and xanthine. One unit (U) of SOD represents the amount of enzyme needed to inhibit $50 \%$ of the dismutation of superoxide radicals.

CAT activity was measured by the Catalase Assay Kit (Cayman Chemical, Ann Arbor, MI, USA), which utilizes the peroxidase function of CAT for determination of enzyme activity. It is based on an enzyme reaction with methanol in the optimal concentration of hydrogen peroxide. One unit (U) of CAT activity is defined as the amount of enzyme that results in the formation of $1 \mathrm{nM}$ of formaldehyde per minutes at $25^{\circ} \mathrm{C}$.

The glutathione peroxidase (GPX) activity was determined using a glutathione peroxide assay kit (Cayman Chemical, Ann Arbor, MI, USA) according to the manufacturer's instructions. The assay indirectly measures GPx activity using a coupled reaction with GSH reductase by monitoring the oxidation of reduced $\mathrm{NADPH}$ at $340 \mathrm{~nm}$. One unit (U) of GPx activity is defined as the amount of enzyme that will oxidize $1.0 \mathrm{nM}$ of NADPH per minutes at $25^{\circ} \mathrm{C}$. GPx activity was calculated using the actual extinction coefficient for NADPH at $340 \mathrm{~nm}\left(6.22 \times 10^{6} \mathrm{M}^{-1} \cdot \mathrm{cm}^{-1}\right)$. Enzyme activities are expressed as $\mathrm{U}$ per $\mathrm{mg}$ tissue protein.

\section{Histology and immunohistochemistry}

The liver, kidney, and lung tissues were fixed in 10\% buffered formalin solution and embedded in paraffin. Tissue specimens were cut into sections $5-\mu \mathrm{m}$ thick and stained with hematoxylin and eosin. For immunohistochemical analysis, the sections were incubated with 3\% hydrogen peroxide in absolute methanol for 10 minutes at room temperature, followed by 30 minutes of incubation with $3 \%$ bovine serum albumin in PBS. All tissue sections were incubated with primary antibodies against nitrotyrosine (Millipore, Billerica, MA, USA) for 1 hour at room temperature in a humidified chamber. After washing thrice with PBS containing $0.05 \%$ Tween-20, the specimens were incubated with horseradish peroxidase-conjugated antibody (Zymed Lab., San Francisco, CA, USA), and then stained with 3,3-diaminobenzidine as chromogen (Life Science Division, Mukileto, WA, USA). The sections were counterstained with Mayer's hematoxylin and evaluated with the Zeiss Axio Imager microscope.

\section{Statistical analysis}

Data is expressed as the mean \pm SE (SEM). Groups of data were compared with one-way ANOVA followed by Tukey's multiple comparison test. $P$-values of less than 0.05 were considered statistically significant. Statistical analysis was performed with IBM SPSS software ver. 21 (IBM Co., Endicott, NY, USA).

\section{RESULTS}

1. Effect of white-fleshed peach on the excretion of nicotine metabolites and 1-hydroxypyrene in the urine of smokers

Nicotine is metabolized into several metabolites and excreted in the urine. Cotinine, the major metabolite of nicotine, is a sensitive and specific biochemical marker of exposure to cigarette smoke. The main metabolite of PAHs, 1-hydroxypyrene, is preferentially used as a biomarker of carcinogen exposure such as cigarette smoke. ${ }^{17}$ As shown in Figure 1A, intake of white-fleshed peaches increased the concentration of nicotine metabolites excreted in the urine of 11 out of 12 smoker volunteers (91.67\%), compared to levels before intake (control). Salivary cotinine concentration was used for correction of urinary nicotine metabolite concentration. Intake of white-fleshed peaches raised the urinary level of 1-hydroxypyrene excreted from 10 out of 12 smoker volunteers (83.33\%) (Fig. 1B). Urinary 1-hydroxypyrene concentration was corrected by urinary creatinine concentration. Intake of white-fleshed peaches did not have a remarkable effect on the average salivary and plasma cotinine concentrations, although salivary and plasma cotinine concentrations showed individual differences. 

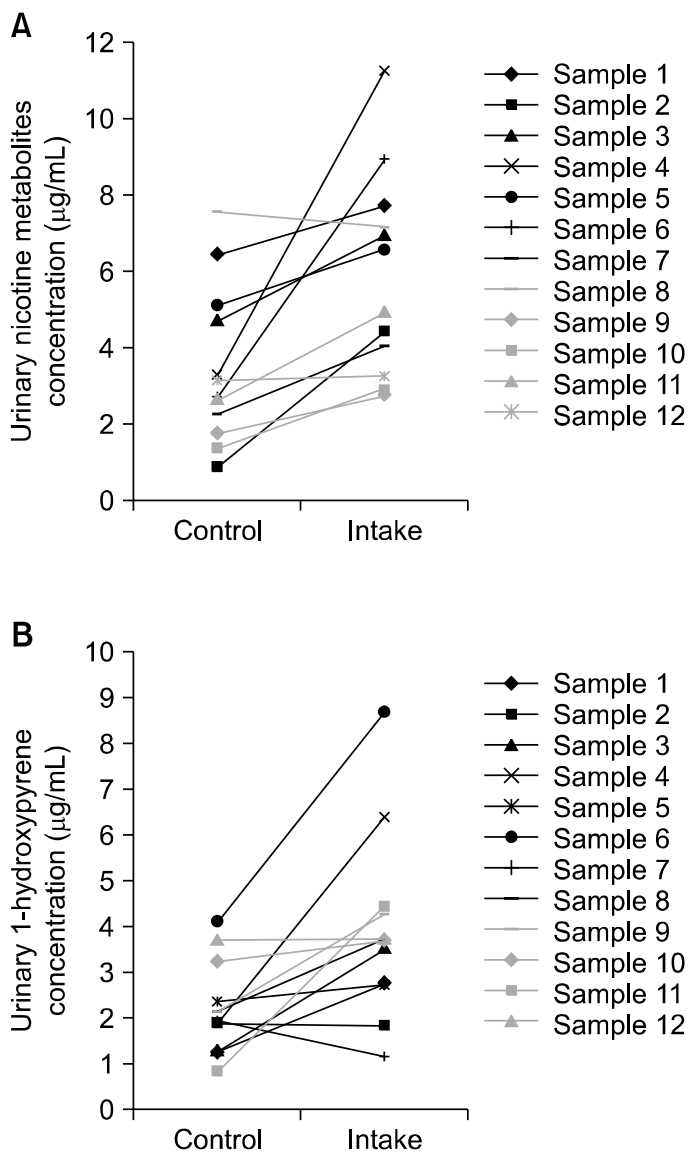
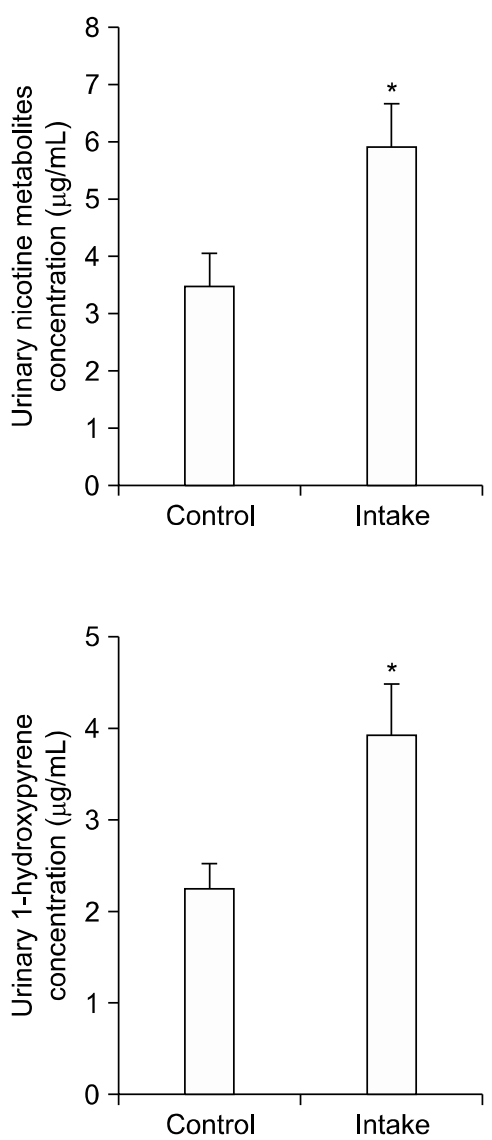

Figure 1. Effect of white-fleshed peach on the excretion of nicotine metabolites and 1-hydroxypyrene in urine of smokers. Urine and saliva of subjects were collected before intake of white-fleshed peach and 4 days after intake. (A) Nicotine metabolite concentration in urine and cotinine concentration in saliva were measured by the colorimetric method and the enzyme immunoassay, respectively. (B) The 1-hydroxypyrene and creatinine concentrations in urine were measured by high-performance liquid chromatography analysis and colorimetric method, respectively. Urinary nicotine metabolite concentration and 1-hydroxypyrene concentration were corrected by salivary cotinine concentration and urinary creatinine concentration, respectively. Data are expressed as mean \pm SEM. $* P<0.05$ versus control (before intake).

\section{Effect of white-fleshed peach extracts on nephro- toxicity and hepatotoxicity in nicotine-injected mice}

We conducted an animal experiment to study the effect of white-fleshed peaches on tissue toxicity by chronic nicotine treatment. First, to evaluate the effect of nicotine toxicity and WFPE administration on body weight, we measured the weights of all mice every other day during the experimental period. Body weights of the control mice gradually increased, while the nicotine group gained weight up to day 20 and lost weight thereafter until the end of the experiment (data not shown). However, administration of WFPE restored the decreased body weight in nicotine-injected mice.

The protective effect of WFPE against chronic nicotine-induced renal and hepatic toxicity was assessed by measuring biochemical parameters in sera of the mice. We analyzed BUN and creatinine levels for kidney function, and AST and ALT levels for liver function. The mice treated with WFPE alone did not show any kidney or liver dysfunction, but nicotine raised the levels of all biochemical parameters in the mouse sera (Fig. 2). In contrast, WFPE treatment dose-dependently lowered serum levels of BUN, creatinine, AST, and ALT that were elevated by nicotine. In particular, the serum BUN and ALT levels were recovered almost to control levels at a WFPE dosage of $500 \mathrm{mg} / \mathrm{kg}$.

\section{Effect of white-fleshed peach extracts on oxidative damages in liver and kidney tissues of nicotine-in- jected mice}

To investigate the effect of WFPE on chronic-induced oxidative tissue damages, MDA, and GSH contents, as well as antioxidant enzyme activities, were measured in the liver and kidney tissue homogenates from all the mice. The level of MDA, which is a major degradation product of lipid peroxidation, increased after chronic nicotine treatment when compared to the control group (Fig. 3A). However, administration of higher-dose WFPE to nicotine-injected mice significantly reduced tissue MDA levels and showed a more pronounced reduction effect in the liver than the kidney.

The antioxidative status was assessed by measuring GSH content and the activities of antioxidant enzymes in the liver and kidney tissues. In the nicotine-injected mice, the level of GSH and the activities of SOD, GPx, and CAT were significantly lower than 

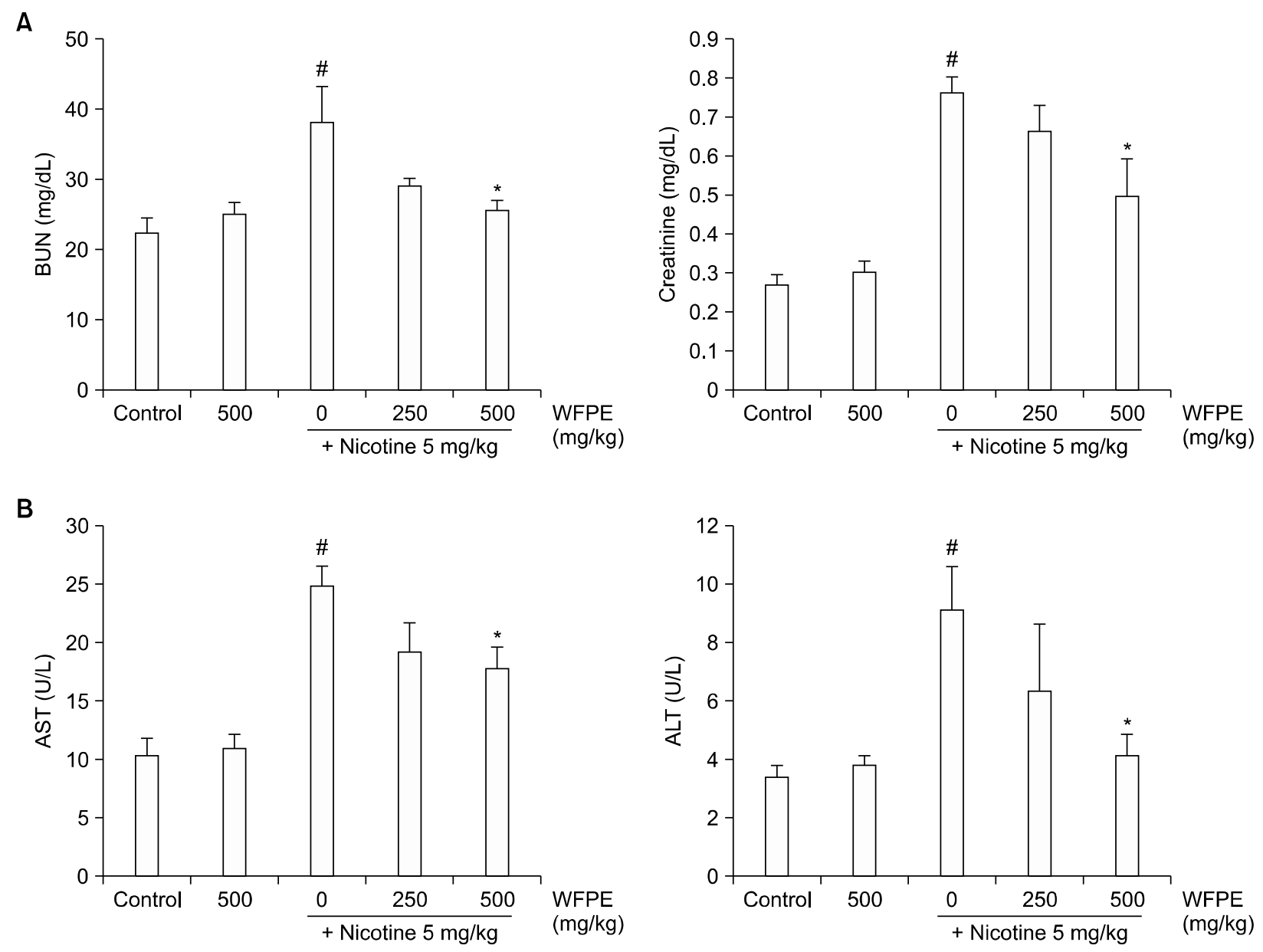

Figure 2. Effect of white-fleshed peach extracts (WFPE) on chronic nicotine-induced nephrotoxicity and hepatotoxicity in mice. Nicotine $(5$ $\mathrm{mg} / \mathrm{kg}$ body weight [BW]) and/or WFPE $(250 \mathrm{mg} / \mathrm{kg} \mathrm{BW}$ or $500 \mathrm{mg} / \mathrm{kg} \mathrm{BW})$ were administered to mice $(\mathrm{n}=6)$ once daily for 5 weeks. The control mice $(\mathrm{n}=6$ ) received saline alone. (A) The serum blood urea nitrogen (BUN) and creatinine levels were measured using commercially available kits for analysis of nephrotoxicity. (B) The serum levels of alanine aminotransferase (ALT) and aspartate aminotransferase (AST) were analyzed as evidence of hepatotoxicity. Data are expressed as mean $\pm \operatorname{SEM}\left(\mathrm{n}=6\right.$ per group). ${ }^{\#} P<0.05$ versus control group; ${ }^{*} F$ $<0.05$ versus nicotine group.

the control group (Fig 3B and 3C). The WFPE-treated group showed recovery of GSH levels and antioxidant enzyme activities.

\section{Effect of white-fleshed peach extracts on nicotine- induced histological changes and nitrotyrosine ex- pression in liver, kidney, and lung tissues}

Histological analysis revealed that chronic nicotine administration resulted in significant tissue damage and changes when compared to the tissues of control mice (Fig. 4A). Microscopic evaluation of the liver in the control group showed hepatocytes arranged in rows that radiate out from the central vein. In the liver tissues of nicotine-injected mice, however, severe necrosis of hepatocytes and infiltration of inflammatory cells were present; additionally, sinusoidal congestion was observed. Treatment with WFPE at $250 \mathrm{mg} / \mathrm{kg}$ reduced necrosis and showed moderate infiltration of inflammatory cells. In the liver sections of the higher dose WFPE-treated mice, inflammatory cell infiltrates were rare, and necrosis was not observed. The normal kidney samples showed prominent regular structures of glomeruli and renal tubules. In the nicotine alone group, kidney sections showed vacuolation of tubular cells and wide dilatations in the glomeruli. Treatment with WFPE dose-dependently inhibited the morphologic changes induced by nicotine.

In the lung tissue, the control group showed normal alveoli with thin alveolar septa. However, nicotine treatment induced edema, moderate hemorrhage, and a remarkable thickening of the alveolar septa with hyperplasia of the 
A

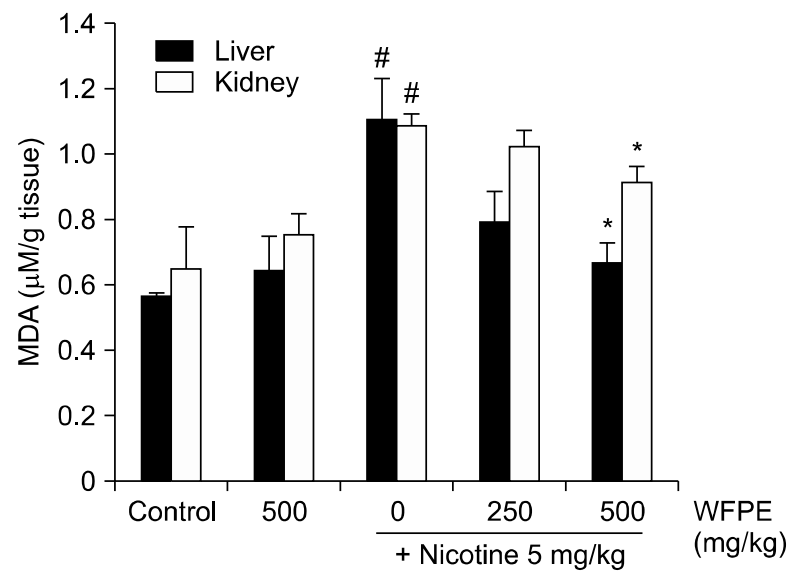

C

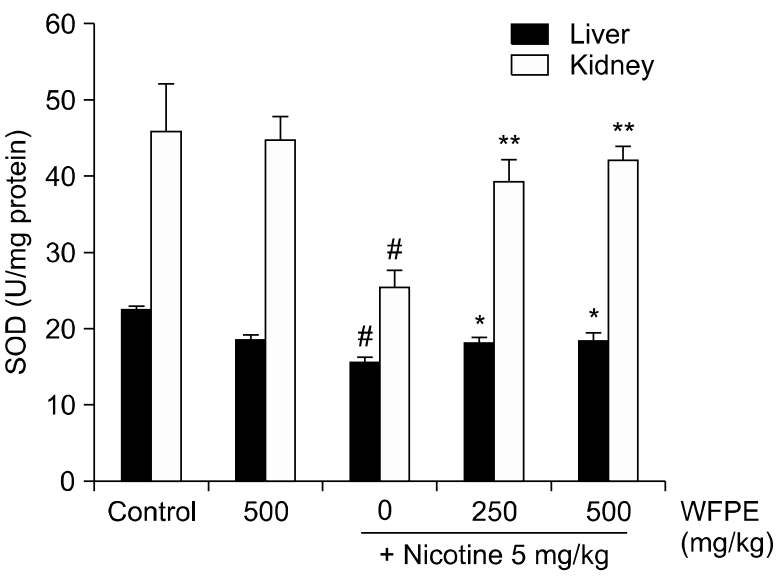

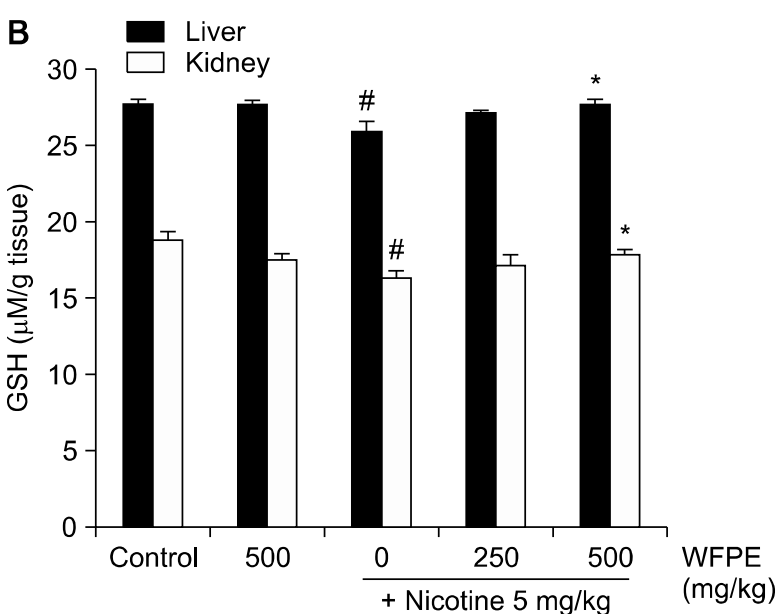

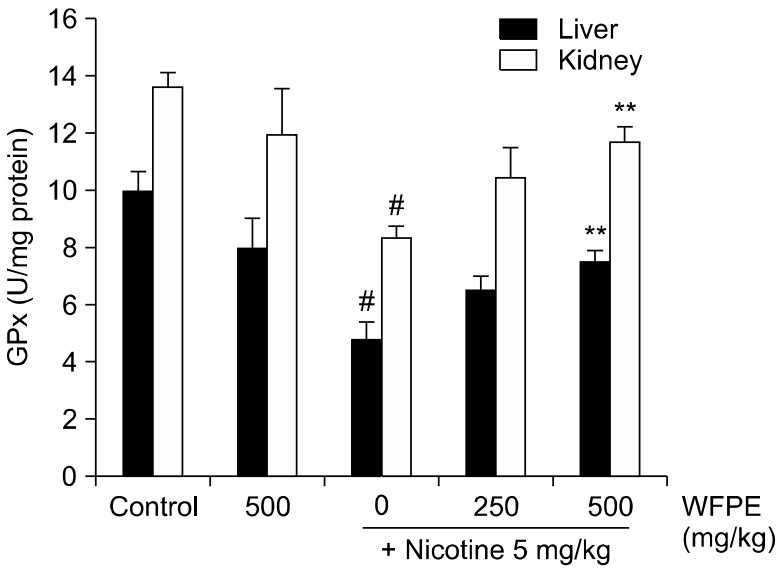

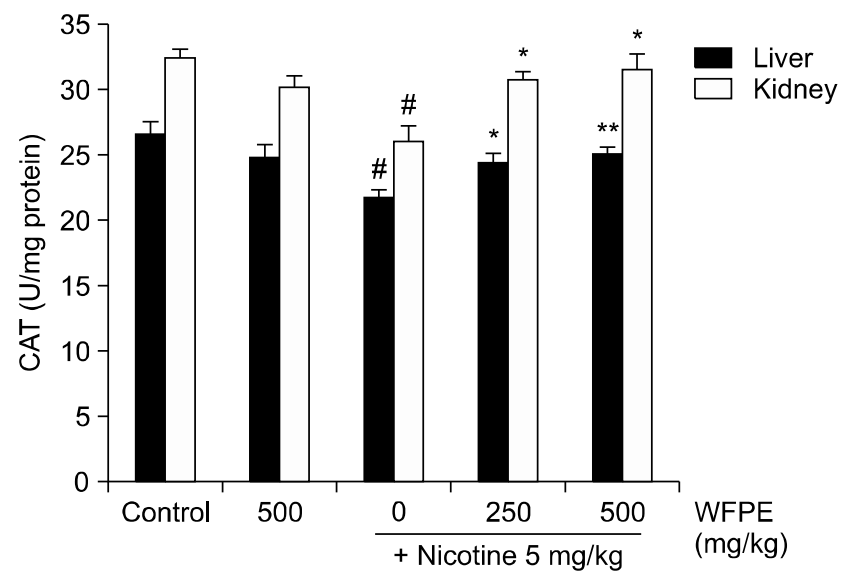

Figure 3. Effect of white-fleshed peach extracts (WFPE) on chronic nicotine-induced oxidative stress in mouse tissues. After mice were administrated nicotine $(5 \mathrm{mg} / \mathrm{kg}$ body weight [BW] ) and/or WFPE $(250 \mathrm{mg} / \mathrm{kg}$ BW or $500 \mathrm{mg} / \mathrm{kg} \mathrm{BW})$ for 5 weeks, liver and kidney tissues were collected and homogenized. (A) The level of malondialdehyde (MDA), as an indicator of lipid peroxidation, was measured in tissue homogenates. (B) Glutathione (GSH) content was evaluated by the reaction with Ellman's reagent. (C) Among the enzymatic antioxidants, superoxide dismutase (SOD), glutathione peroxidase (GPx), and catalase (CAT) were analyzed by commercial available kits, respectively. Data are expressed as mean $\pm \operatorname{SEM}\left(\mathrm{n}=6\right.$ per group). ${ }^{\#} P<0.05$ versus control group; $* P<0.05,{ }^{*} P<0.01$ versus nicotine group. 

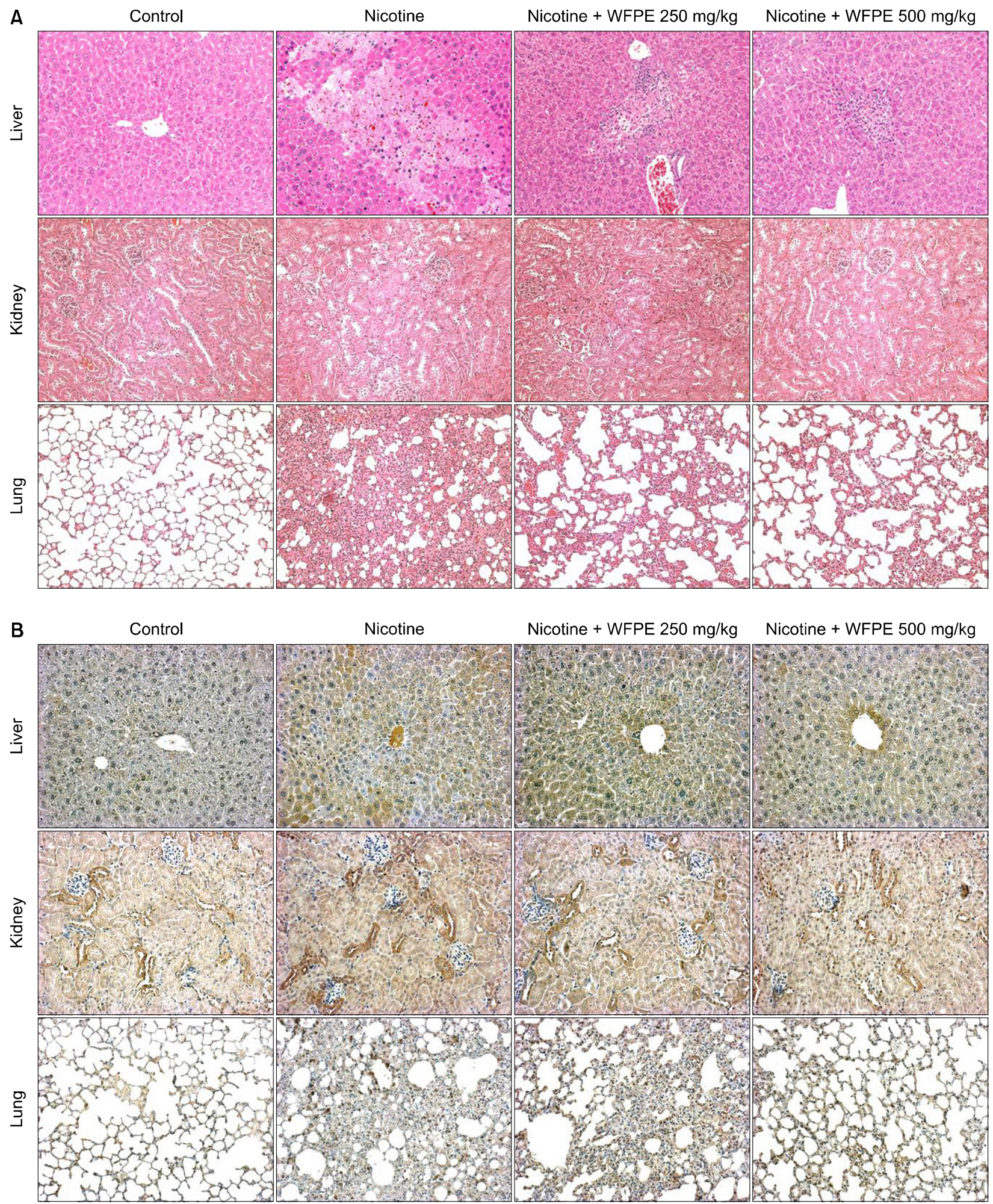

Figure 4. Effect of white-fleshed peach extracts (WFPE) on histological changes and nitrotyrosine expression in the liver, kidney, and lung tissues of chronic nicotine-injected mice. The liver, kidney, and lung tissues from mice, which were administrated nicotine $(5 \mathrm{mg} / \mathrm{kg}$ body weight [BW]) and/or WFPE (250 mg/kg BW or $500 \mathrm{mg} / \mathrm{kg} \mathrm{BW})$ for 5 weeks, were fixed and stained. (A) The morphological features of tissue sections were evaluated by Hematoxylin and eosin staining $(\times 200)$. (B) Nitrotyrosine expressions were evaluated by immunohistochemistry $(\times 200)$. 
epithelial cells. WFPE treatment in nicotine-injected mice reduced thickening of the alveolar septa and edema in a dose-dependent manner.

We immunohistochemically analyzed the expression of nitrotyrosine in the liver, kidney, and lung tissues of the control mice and nicotine-injected mice with or without WFPE treatment (Fig. 4B). Substantially enhanced levels of nitrotyrosine were observed in three tissues of nicotine-injected mice. However, WFPE treatment dose-dependently inhibited nicotine-induced nitrotyrosine formation.

\section{DISCUSSION}

Tobacco smoking was recognized as a major cause of mortality and morbidity since environmental tobacco smoke was found to be a human lung carcinogen by the US Environmental Protection Agency in 1992. Over 4,000 chemicals have been identified in tobacco smoke, including 69 known carcinogens and hundreds that are hazardous. ${ }^{18}$ It has been reported that nicotine, a major component of tobacco smoke and a highly addictive drug, plays an important role in the development of cardiovascular and lung diseases. ${ }^{5,19,20}$ As nicotine enters the human body through tobacco smoking, it is efficiently absorbed into the bloodstream through the lungs and rapidly delivered to the brain. ${ }^{21}$ Nicotine is also absorbed through the mucosal lining of the mouth and nose, and even through the skin. Nicotine is extensively metabolized to a number of metabolites; cotinine, the primary metabolite of nicotine, is formed after C-oxidation by hepatic cytochrome $\mathrm{P} 450$ (CYP2A6). ${ }^{22}$ Cotinine is further metabolized by the same enzyme system as trans-3'-hydroxycotinine (hydroxycotinine) and other minor metabolites including norcotinine. ${ }^{23}$ PAHs, including the widely studied benzo[a]pyrene, are considered the main carcinogens of cigarette smoke. PAHs bind to aryl hydrocarbon receptor after entering the body, and induce cytochrome P450 drug-metabolizing enzymes, such as CYP1A1, CYP1A2, CYP1Ba, and CYP3A4, which metabolize PAHs into various PAH derivatives, such as hydroxylated PAHs and $\mathrm{PAH}$ quinones. ${ }^{24}$ Urinary 1-hydroxypyrene, a monohydroxylated metabolite of pyrene, has been widely used as a biomarker of total PAH uptake in smokers and nonsmokers. ${ }^{25}$

The intake of fruits and vegetables, including flavonoids, is closely related to the prevention and reduction in the risk of chronic diseases, such as inflammation, various cancers, and cardiovascular disorders. P. persica fruits have moderate effects on blood circulation, recovery from exhaustion, detoxification, reinforcement of immune ability, and cosmetic treatment of the skin. ${ }^{26}$ However, the effect of $P$. persica fruits on the detoxification of smoking has not yet been reported. Thus, we firstly investigated whether white-fleshed peaches have effects on the excretion of nicotine metabolites and 1-hydroxypyrene in the urine of smokers. Intake of white-fleshed peaches increased the concentration of nicotine metabolites in the urine of $91.67 \%$ of smokers. In addition, the concentration of urinary 1-hydroxypyrene, the major metabolite of $\mathrm{PAH}$, increased in $83.33 \%$ of smokers after intake of peach fruit. Thus, intake of white-fleshed peaches increased the excretion of nicotine metabolites and 1-hydroxypyrene in the smokers. Therefore, intake of white-fleshed peaches and related processed foods might be an effective method for the detoxification of nicotine in smokers and nonsmokers who are exposed to environmental tobacco smoke.

Nicotine, a major pharmacologically active component of tobacco smoke, triggers an accumulation of free radicals or ROS, and consequently causes oxidative stress, cytotoxicity, and tissue damage. In our animal study, chronic nicotine exposure inhibited a gain of body weight, but this weight loss was blocked in the mice that were administered extracts of white-fleshed peach at 250 $\mathrm{mg} / \mathrm{kg}$ or $500 \mathrm{mg} / \mathrm{kg}$ body weight. These results indicate that chronic nicotine exposure eventually induces systemic toxicity, and WFPE can suppress nicotine toxicity by being absorbed into the bodies of animals.

The liver and kidney are highly susceptible to the oxidative stress associated with the toxicity of nicotine. Our results showed that chronic nicotine exposure caused hepatic and renal damage associated with an accumulation of lipid peroxidation products. However, WFPE treatment dose-dependently inhibited nephrotoxicity and hepatotoxicity by reducing serum levels of BUN, creatinine, AST, and ALT. A high-dose of WFPE did not affect the functional index of the liver and kidney in normal mice, but did reduce nicotine-increased levels of BUN and ALT to levels similar to the control group. In addition, a marked increase in the MDA level was identified in the liver and kidney homogenates of mice chronically exposed to nicotine; oral administration of WFPE blocked this increase. Furthermore, WFPE treatment blocked the decrease of GSH content and inhibition of antioxidant enzymes activities, including SOD, GPx, and CAT, in the liver and kidney tissues of nicotine-injected mice. These results show that orally administered WFPE attenuates oxidative stress by preventing nicotine-induced reductions in GSH content and the activities of antioxidant enzymes.

The lung, the primary site exposed to tobacco smoke, is highly susceptible to free radical generation. Our histological data 
showed nicotine-induced toxicity in the lung tissue, as well as in the liver and kidney tissues, but organ damages caused by nicotine were decreased by WFPE treatment. In immunohistochemistry, nitrotyrosine, a biomarker of oxidative stress, was positively expressed in the liver, kidney, and lung tissues of nicotine-injected mice, while its expression was dose-dependently suppressed in the WFPE-treated group. Nitrotyrosine is formed on tyrosine residues by toxic peroxynitrite derived from nitric oxide (NO) and superoxide anion $\left(\mathrm{O}_{2}{ }^{-}\right)$, which is elevated in conditions of oxidative stress in many diseases, such as inflammation, cytotoxicity, and cancer. ${ }^{27}$ Therefore, inhibition of nicotine-induced nitrotyrosine formation by WFPE treatment indicates a decrease of oxidative stress.

In conclusion, WFPE may mitigate nicotine toxicity by promoting the excretion of nicotine metabolites. The protective effect of WFPE against tissue damages by chronic nicotine exposure, may be mediated through the inhibition of oxidative stress by enhancing of antioxidant capacities. Thus, white-fleshed peach may be a beneficial supplement for smokers.

\section{CONFLICTS OF INTEREST}

No potential conflicts of interest were disclosed.

\section{REFERENCES}

1. Hecht SS. Tobacco carcinogens, their biomarkers and tobacco-induced cancer. Nat Rev Cancer 2003;3:733-44.

2. Bringuier PP, McCredie M, Sauter G, Bilous M, Stewart J, Mihatsch MJ, et al. Carcinomas of the renal pelvis associated with smoking and phenacetin abuse: p53 mutations and polymorphism of carcinogen-metabolising enzymes. Int J Cancer 1998;79:531-6.

3. Joshi HN, Makaju R, Karmacharya A, Karmacharya RM, Shrestha $B$, Shrestha $\mathrm{R}$, et al. Urinary bladder carcinoma: impact of smoking, age and its clinico-pathological spectrum. Kathmandu Univ Med J (KUMJ) 2013:11:292-5.

4. Xu Y, Qi Y, Zhang J, Lu Y, Song J, Dong B, et al. The impact of smoking on survival in renal cell carcinoma: a systematic review and meta-analysis. Tumour Biol 2014;35:6633-40.

5. Grando SA. Connections of nicotine to cancer. Nat Rev Cancer 2014:14:419-29.

6. Nakada T, Kiyotani K, Iwano S, Uno T, Yokohira M, Yamakawa K, et al. Lung tumorigenesis promoted by anti-apoptotic effects of cotinine, a nicotine metabolite through activation of PI3K/Akt pathway. J Toxicol Sci 2012;37:555-63.

7. Yuen ST, Gogo AR Jr, Luk IS, Cho CH, Ho JC, Loh TT. The effect of nicotine and its interaction with carbon tetrachloride in the rat liver. Pharmacol Toxicol 1995:77:225-30.
8. Tsutsumi K. Lipoprotein lipase and atherosclerosis. Curr Vasc Pharmacol 2003;1:11-7.

9. Latha MS, Vijayammal PL, Kurup PA. Effect of nicotine administration on lipid metabolism in rats. Indian J Med Res 1993; 98:44-9.

10. Ashakumary L, Vijayammal PL. Additive effect of alcohol and nicotine on lipid peroxidation and antioxidant defence mechanism in rats. J Appl Toxicol 1996;16:305-8.

11. Fukuda T, Ito H, Mukainaka T, Tokuda H, Nishino H, Yoshida T. Anti-tumor promoting effect of glycosides from Prunus persica seeds. Biol Pharm Bull 2003:26:271-3.

12. Shin TY, Park SB, Yoo JS, Kim IK, Lee HS, Kwon TK, et al. Anti-allergic inflammatory activity of the fruit of Prunus persica: role of calcium and NF-kappaB. Food Chem Toxicol 2010;48:2797-802.

13. Lee CK, Park KK, Hwang JK, Lee SK, Chung WY. The pericarp extract of Prunus persica attenuates chemotherapy-induced acute nephrotoxicity and hepatotoxicity in mice. J Med Food 2008; 11:302-6.

14. Lee CK, Park KK, Hwang JK, Lee SK, Chung WY. Extract of Prunus persica flesh (PPFE) improves chemotherapeutic efficacy and protects against nephrotoxicity in cisplatin-treated mice. Phytother Res 2009:23:999-1005.

15. Ohkawa H, Ohishi N, Yagi K. Assay for lipid peroxides in animal tissues by thiobarbituric acid reaction. Anal Biochem 1979;95: 351-8.

16. Sedlak J, Lindsay RH. Estimation of total, protein-bound, and nonprotein sulfhydryl groups in tissue with Ellman's reagent. Anal Biochem 1968:25:192-205.

17. Hecht SS, Carmella SG, Le KA, Murphy SE, Li YS, Le C, et al. Effects of reduced cigarette smoking on levels of 1-hydroxypyrene in urine. Cancer Epidemiol Biomarkers Prev 2004;13:834-42.

18. Hoffmann D, Hoffmann I, El-Bayoumy K. The less harmful cigarette: a controversial issue. a tribute to Ernst L. Wynder. Chem Res Toxicol 2001;14:767-90.

19. Heusch WL, Maneckjee R. Signalling pathways involved in nicotine regulation of apoptosis of human lung cancer cells. Carcinogenesis 1998;19:551-6.

20. Balakumar P, Kaur J. Is nicotine a key player or spectator in the induction and progression of cardiovascular disorders? Pharmacol Res 2009;60:361-8.

21. Nakayama H. Nicotine metabolism in mammals. Drug Metabol Drug Interact 1988;6:95-122.

22. Nakajima M, Yamamoto $T$, Nunoya $K$, Yokoi T, Nagashima $K$, Inoue $\mathrm{K}$, et al. Role of human cytochrome P4502A6 in C-oxidation of nicotine. Drug Metab Dispos 1996;24:1212-7.

23. Kyerematen GA, Vesell ES. Metabolism of nicotine. Drug Metab Rev 1991;23:3-41.

24. Bekki K, Toriba A, Tang N, Kameda T, Hayakawa K. Biological effects of polycyclic aromatic hydrocarbon derivatives. J UOEH 2013:35:17-24.

25. Jacob P 3rd, Wilson M, Benowitz NL. Determination of phenolic metabolites of polycyclic aromatic hydrocarbons in human urine as their pentafluorobenzyl ether derivatives using liquid chromatography-tandem mass spectrometry. Anal Chem 2007;79:587-98.

26. Kono R, Okuno Y, Nakamura M, Inada K, Tokuda A, Yamashita M, et al. Peach (Prunus persica) extract inhibits angiotensin II-in- 
duced signal transduction in vascular smooth muscle cells. Food Chem 2013;139:371-6.

27. Ischiropoulos H. Biological tyrosine nitration: a pathophysio- logical function of nitric oxide and reactive oxygen species. Arch Biochem Biophys 1998;356:1-11. 